\title{
Neutronic Performance of the VVER-1000 Reactor Using Thorium Fuel with ENDF Library
}

\author{
Sonia M. Reda $\mathbb{D}^{1}{ }^{1}$ Ibrahim M. Gomaa, ${ }^{2}$ Ibrahim I. Bashter, ${ }^{1}$ and Esmat A. Amin ${ }^{3}$ \\ ${ }^{1}$ Physics Department, Faculty of Science, Zagazig University, Zagazig, Egypt \\ ${ }^{2}$ Zagazig Higher Institute for Engineering and Technology, Zagazig, Egypt \\ ${ }^{3}$ Nuclear and Radiological Regulatory Authority, Cairo, Egypt \\ Correspondence should be addressed to Sonia M. Reda; smali@ju.edu.sa
}

Received 13 April 2020; Revised 7 February 2021; Accepted 29 March 2021; Published 15 April 2021

Academic Editor: Arkady Serikov

Copyright ( $\odot 2021$ Sonia M. Reda et al. This is an open access article distributed under the Creative Commons Attribution License, which permits unrestricted use, distribution, and reproduction in any medium, provided the original work is properly cited.

In this paper, neutronic calculations and the core analysis of the VVER-1000 reactor were performed using MCNP6 code together with both ENDF/B-VII.1 and ENDF/B-VIII libraries. The effect of thorium introduction on the neutronic parameters of the VVER-1000 reactor was discussed. The reference core was initially filled with enriched uranium oxide fuel and then fueled with uranium-thorium fuel. The calculations determine the delayed neutron fraction $\beta_{\mathrm{eff}}$, the temperature reactivity coefficients, the fuel consumption, and the production of the transuranic elements during reactor operation. $\beta_{\text {eff }}$ and the Doppler coefficient (DC) are found to be in agreement with the design values. It is found that the core loaded with uranium and thorium has lower delayed neutron fraction than the uranium oxide core. The moderator temperature coefficients of the uranium-thorium core are found to be higher than those of the uranium core. Results indicated that thorium has lower production of minor actinides (MAs) and transuranic elements (mainly plutonium isotopes) compared with the relatively large amounts produced from the uranium-based fuel $\mathrm{UO}_{2}$.

\section{Introduction}

Countries are building nuclear power plants to meet their energy needs; the site of nuclear power plant in Egypt is El Dabaa. The VVER-1200 is the predecessor of the VVER1000 reactor. The VVER-1000 is a $3000 \mathrm{MW}$ thermal power nuclear power plant which is cooled and moderated by light water. The core is filled with 163 enriched uranium $\left(\mathrm{UO}_{2}\right)$ fuel assemblies (FAs). The reactor includes international safety standards with evolutionary design improvement in the areas of fuel technology, modularized construction, safety systems, and standardized designs $[1,2]$.

In fact, thorium is three times more abundant than uranium, and the feasibility of loading the core with thorium uranium fuel was carried out. Thorium is made up mainly of "fertile" isotope $\left({ }^{232} \mathrm{Th}\right)$. Experiments have been made on power reactors that were successfully operated using $\mathrm{ThO}_{2^{-}}$ $\mathrm{UO}_{2}$ fuel in light water reactors (LWRs). ${ }^{233} \mathrm{U}$ and ${ }^{232} \mathrm{Th}$ are the best "fissile" and "fertile" materials, respectively, for thermal neutron reactors [3].
The neutronic parameter effects due to loading thorium as a part of VVER-1200 fuel under normal operation were studied by Dwiddar et al. [4]. The investigation used two different configurations, mixed uranium fuel with thorium and seed-blanket fuel. The amount of thorium inserted and the location of the thorium assemblies in the core of the reactor presented the master factor in determining the value of $k_{\text {eff }}$ and the core cycle length. The results concluded that the safest position of thorium is in the periphery of the core, and it is recommended to provide a blanket of mixed thorium uranium fuel for the entire core as the peripheral layer with the highest value of uranium enrichment. Mixing thorium with plutonium instead of uranium for the uranium enrichment, limited to $5 \%$, was suggested.

Minimizing the fission products (FPs) using thorium as a fuel in place of the traditional $\mathrm{UO}_{2}$ fuel has been studied by Galahom [5]. This paper discussed the VVER-1200 neutronic features for one assembly. The assembly fuel is a mix of thorium (fertile) with uranium (fissile). The neutronic features were calculated and compared with the traditional 
$\mathrm{UO}_{2}$ fuel by using MCNPX code. The purpose of this study is to minimize the production of long-lived actinides and improve the fuel cycle length. The moderator temperature coefficient and the percentage of fissile inventory have been measured at different burn steps. The results showed that thorium fuels were better than $\mathrm{UO}_{2}$, and by replacing ${ }^{238} \mathrm{U}$ with ${ }^{232} \mathrm{Th}$, we need much ${ }^{235} \mathrm{U}$ as a fissile material to sustain the same burnup level. For ${ }^{232} \mathrm{Th}+{ }^{235} \mathrm{U}$ fuel, the Doppler coefficient (DC) was more negative [5]. Production of longlived actinides using thorium, fertile material, was reduced.

The possible advantages of the seed-blanket (SB) assembly used in the VVER-1200 core instead of the homogeneous assembly were investigated using MCNPX 2.7 code and the ENDF/B-VII library [6]. The blanket region fertile material was ${ }^{232} \mathrm{Th}$, while in the seed region, four different fissile materials have been investigated. The work concluded that in the homogeneous assembly, the power distribution is flatter than that of the heterogeneous assembly. The suggested fuels achieved a longer fuel cycle and a higher conversion ratio in the SB assembly than the homogeneous assembly. Moreover, using ${ }^{232} \mathrm{Th}$ instead of ${ }^{238} \mathrm{U}$ resulted in reducing the plutonium and the production of transuranic atoms.

Heterogeneous and homogeneous seed-blanket concepts were used to study the thermal hydraulics feasibility and the neutronics to change the AP1000 PWR reactor from $\mathrm{UO}_{2}$ to (U-Th) $\mathrm{O}_{2}$ [7]. The burnable poison geometry and materials in the core were not varied and only the fuel pin material was varied keeping the low enriched uranium (LEU) for ${ }^{235} \mathrm{U}$. The study used three different fuel types, the first being $68 \%$ $\mathrm{ThO}_{2}-32 \% \mathrm{UO}_{2}$; the second being $76 \% \mathrm{ThO}_{2}-24 \% \mathrm{UO}_{2}$; and the third being $80 \% \mathrm{ThO}_{2}-20 \% \mathrm{UO}_{2}$. The work goals were to increase ${ }^{233} \mathrm{U}$ and minimize production of plutonium. The results showed that the homogeneous concept with three distinct types of fuel meets the optimization requirements. The results revealed that (U-Th)O2 hase many benefits, including a lower power density, retaining the same 18 months cycle, and a lower concentration of B-10 in the soluble poison and the elimination of B-10 in the coated integral boron poison [7].

In this paper, the neutronic performance and core analysis of the VVER-1000 one-six core were performed from the beginning of life (BOL) at cold zero power state (CZP) to the end of life (EOL) at hot full power state (HFP). The VVER-1000 reference core was initially filled with enriched uranium oxide fuel and then fueled with uraniumthorium fuel. Since thorium-based fuel is more favorable from the safeguard viewpoint, it is investigated in the present work as a fuel option to increase the fuel cycle length and reduce the plutonium amount produced. The neutronics calculations were made by MCNP6 code with two cross section libraries ENDF/B-VII.1 and ENDF/B-VIII.

\section{The VVER-1000 Reactor Core Description}

The VVER-1000 reactor type is a four-loop Russian version of the pressurized water reactor (PWR) producing about $1000 \mathrm{MW}$ electric power. Figure 1 shows the core loading pattern for the first cycle of operation at the beginning of life
(BOL) [8]. The reactor fresh core consists of FAs, which differ from one another by the enrichment of the fuel. The brief details of the core FAs were illustrated by Aghaie et al. [9]. The reactor core, FA, and fuel rod characteristics are shown in Table 1 [10].

In order to provide lower center temperatures and a free volume to allow any released fission gas to expand and thus decrease internal pressure, the fuel contains a central void hole in its fuel pellet [11]. The form of FAs, numbers, and average enrichment loaded for the first cycle of operation are shown in Table 2 [12].

The core configuration for the mixed thorium-uranium fuel used in this simulation is shown in Figure 2, where the $3^{\text {rd }}$ fuel batch with $4.95 \%$ enrichment is composed of $50 \%$ $\mathrm{UO}_{2}$ and $50 \% \mathrm{ThO}_{2}$.

\section{Methods of Calculation and Validation}

MCNP6 is the result of merging MCNP5 and MCNPX codes with new available options capabilities and features. MCNP6 includes more capabilities such as Shannon entropy, more options for tally treatments and tagging, variance reduction control methods, and more options for geometry and particles. This code is high fidelity due to its accuracy in simulating geometries and materials with continuous energy processing of nuclear parameters [13].

The largest update to the ENDF library is represented in ENDF/B-VIII. These neutron sublibraries have been expanded by $32 \%$ to include 557 evaluations. ENDF/B-VIII and ENDF/B-VII.1 were the libraries used in this study $[14,15]$.

In this study, the VVER-1000 one-six core shown in Figure 3 was simulated. It was fueled firstly with $\mathrm{UO}_{2}$ and then fueled with $\mathrm{ThO}_{2}+\mathrm{UO}_{2}$. The neutronic parameters are presented for the two fuels. The simulation performed used 100000 neutron per cycle, 150 skipped cycles, and 250 active cycles.

$\mathrm{ENDF} / \mathrm{B}-\mathrm{VIII}$ library has the maximum neutron reactions changes on nuclides including actinides which affect nuclear criticality simulations. Two of the most important re-evaluated isotopes are uranium-235 and uranium-238. The re-evaluated parameters include the following.

(i) The capture and fission cross section values: the cross sections for capture reaction have been reduced as compared with ENDF/B-VII.1 in the $0.5-2 \mathrm{keV}$ region, but increased in energies up to $80 \mathrm{keV}$. The fission cross section evaluation agrees with the ENDF/B-VII.1 uncertainties around 0.4\% higher for incident energies less than $15 \mathrm{MeV}[14,16]$.

(ii) The neutron multiplicity: the neutron multiplicity $v$ was re-evaluated and expanded below $30 \mathrm{eV}$ to include fluctuations. Unlike ENDF/B-VII.1 in which $v$ is constant over a wide range of incident neutron energy, there is no constant $v$ in ENDF/BVIII, but its value varied as the incident neutron energy varied $[14,16]$.

(iii) The thermal neutron constants (TNCs): TNC new evaluations for uranium-235 show a neutron multiplicity reduction and a fission cross section 


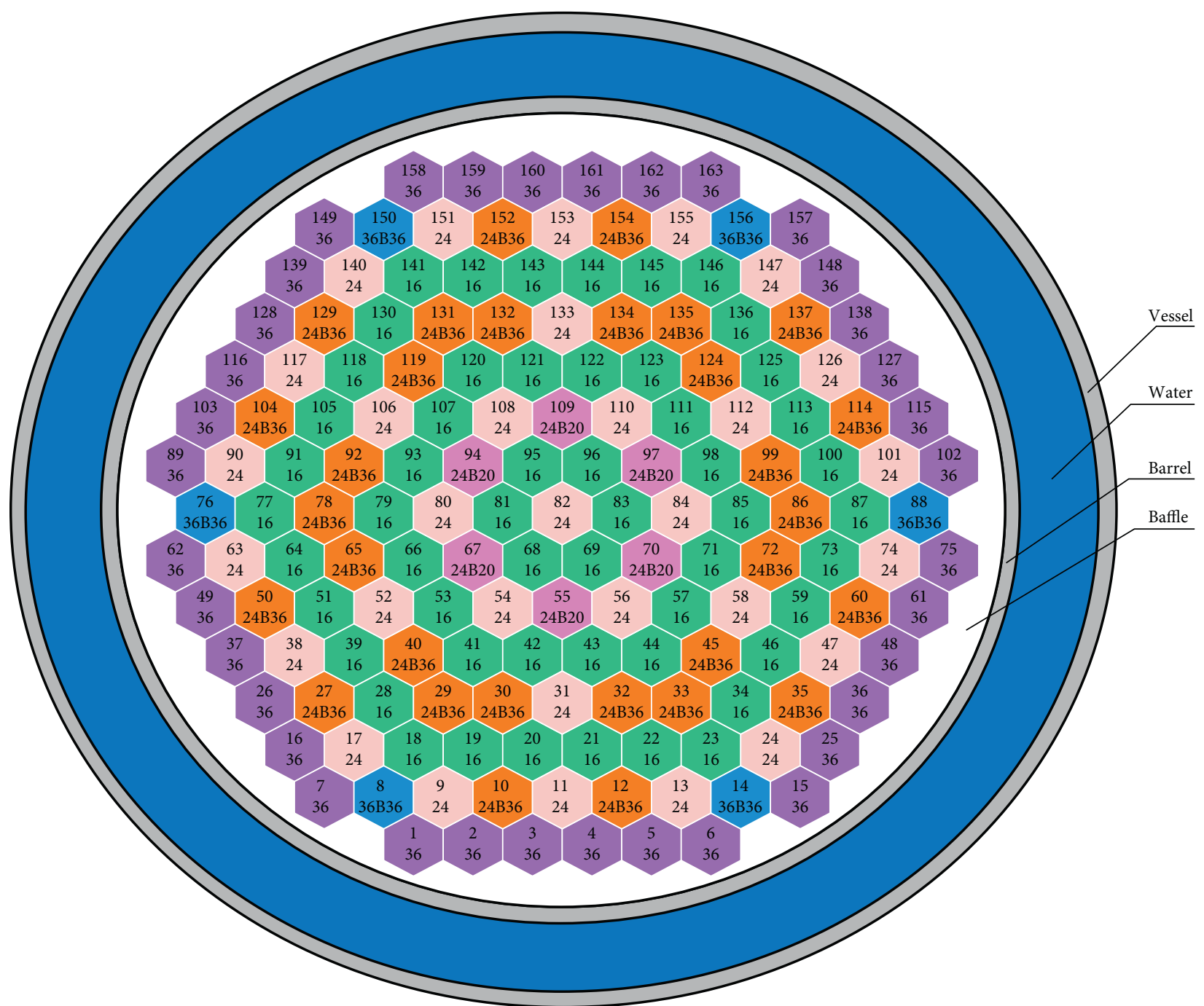

$1.6 \%$ enriched

$2.4 \%$ enriched with $0.02 \mathrm{~g} / \mathrm{cc}$ B.A

$2.4 \%$ enriched

$2.4 \%$ enriched with $0.036 \mathrm{~g} / \mathrm{cc}$ B.A

$3.6 \%$ enriched

$3.6 \%$ enriched with $0.036 \mathrm{~g} / \mathrm{cc}$ B.A

FIGURE 1: Core loading pattern for the first cycle at beginning of cycle (BOC) [8].

increment as compared with ENDF/B-VII.1 evaluations at thermal energy. The comparison between the evaluated thermal neutron constants for ENDF/ B-VII.1, ENDF/B-VIII, and the standard 2017 values $[14,16]$ is illustrated in Table 3 .

(iv) $(\mathrm{n}, \mathrm{f})$ Prompt fission neutron spectrum (PFNS): the ENDF/B-VIII evaluation for the PFNS mean energy is clearly softer than that of ENDF/B-VII.1, but it fits well with experimental data. The new average released neutron energy becomes $2.00 \pm 0.01 \mathrm{MeV}$; on the other hand, it was $2.03 \mathrm{MeV}$ in thermal range [16]. (v) Cross sections of $\left(n, n^{\prime}\right)$ and $(n, x n)$ : the ENDF/BVIII evaluation for the total inelastic scattering cross section $\left(n, n^{\prime}\right)$ is slightly decreased than the last ENDF/B-VII.1 evaluation. ENDF/B-VIII valuation for the $(n, x n)$ secondary neutron was not changed but showed a difference above $14 \mathrm{MeV}$.

(vi) Nubar: evaluators used the parameter nubar to study criticality problems since criticality is highly sensitive to nubar. Several simulations have shown that the use of the new PFNS and TNCs of ENDF/BVIII produces marginally higher $k_{\text {eff }}$ values than those of ENDF/B-VII.1 [17, 18]. 
TABLE 1: Reactor core and fuel assembly design data [10].

\begin{tabular}{lc}
\hline Reactor core & Value \\
\hline Fuel assembly form & Hexagonal \\
Equivalent diameter of the core $(\mathrm{cm})$ & 415 \\
Active height of the fuel $(\mathrm{cm})$ & 353 \\
Fuel assemblies number & 163 \\
Thermal power $(\mathrm{MW})$ & 3000 \\
Coolant/moderator & $\mathrm{H}_{2} \mathrm{O}+\mathrm{H}_{3} \mathrm{BO}_{3}$ \\
Rod pitch $(\mathrm{cm})$ & 1.275 \\
\hline Fuel Assembly $(F A)$ & Value \\
Assembly pitch $(\mathrm{cm})$ & 23.6 \\
Number of pins in the FA & 331 \\
Fuel rods number in the FA & 311 \\
Fuel pin pitch $(\mathrm{cm})$ & 1.275 \\
Length of fuel pin $(\mathrm{cm})$ & 353 \\
Diameter of fuel pellet central hole $(\mathrm{cm})$ & 0.15 \\
Outer/inner diameter of fuel pin $\left(\mathrm{cm}^{2}\right)$ & $0.757 / 0.15$ \\
Outer/inner diameter of cladding $(\mathrm{cm})$ & $0.91 / 0.773$ \\
Outer/inner diameter of guide tube $(\mathrm{cm})$ & $0.126 / 0.106$ \\
Outer/inner diameter of central tube $(\mathrm{cm})$ & $0.13 / 0.11$ \\
Fuel pin material & $\mathrm{UO}{ }_{2}$ \\
Density of fuel pin material $\left(\mathrm{g} / \mathrm{cm}^{3}\right)$ & 10.5 \\
Density of clad material $\left(\mathrm{g} / \mathrm{cm}^{3}\right)$ & 6.4516 \\
Composition of clad material $(\%)$ & $99 \% \mathrm{Zr}, 1 \% \mathrm{Nb}$ \\
Density of guide tube material $\left(\mathrm{g} / \mathrm{cm}^{3}\right)$ & 6.4516 \\
Absorber material & $\mathrm{Boron}$ \\
\hline
\end{tabular}

The above 6 factors explain the marginal increment of ENDF/B-VIII than ENDF/B-VII.1 in the criticality calculations as will be shown in results.

\section{Results and Discussion}

The neutronic calculations of the VVER-1000 reactor are presented starting from the beginning of life (BOL) to the end of life (EOL). At BOL, the reactivity coefficients were estimated. The reactivity coefficients together with the delayed neutron fraction $\beta_{\text {eff }}$ are the key parameters in the reactor dynamics response. The reactivity coefficients include the moderator temperature coefficient (MTC) and Doppler coefficient (DC). The end of life calculations include the burnup results (fuel consumptions and actinide productions). The neutronic parameters were calculated by MCNP6 with ENDF/B-VII.1 and ENDF/B-VIII and compared with the reactor design parameters [19] and published results $[9,20]$. It is necessary for any reactor core to have delayed neutrons since they can control the increase in the reactor power [21]. $\beta_{\text {eff }}$ is calculated by using the following equation:

$$
\beta_{\text {eff }}=\frac{k_{\text {eff }}-k_{\text {prompt }}}{k_{\text {eff }}},
$$

where $k_{\text {prompt }}$ is the effective multiplication factor using only prompt neutrons, while $k_{\text {eff }}$ is the effective multiplication factor using both prompt and delayed neutrons. The fuel temperature coefficient of reactivity (DC) can be calculated by using the following equation:

$$
\mathrm{DC}=\frac{k_{2}-k_{1}}{k_{2}} \frac{1}{\Delta T} \text {. }
$$

$K_{1}$ is calculated in case moderator and fuel are at $300 \mathrm{~K}$ and $k_{2}$ is calculated in case moderator is at $300 \mathrm{~K}$ while fuel is at $600 \mathrm{~K}$ [22]. MTC was determined by the following equation:

$$
\mathrm{MTC}=\frac{k_{3}-k_{2}}{k_{3}} \frac{1}{\Delta T} .
$$

$K_{3}$ is calculated in case fuel and moderator are at $600 \mathrm{~K}$.

4.1. The Beginning of Life (BOL) Results. The comparison between the calculated parameters with the published results is shown in Table 4. This comparison allows assessing the validity of the current VVER-1000 simulation. A general overall good agreement can be observed. In case of fueling the core with $\mathrm{UO}_{2}, \beta_{\text {eff }}$ values were 0.0078 and 0.00688 with ENDF/B-VII.1 and ENDF/B-VIII, respectively, while the expected value from the ${ }^{235} \mathrm{U}$ fission is 0.00650 according to Lamarsh and Baratta [23], so it was realistic to see the core has a delayed neutron fraction that is greater than this expected value. According to RFANE [19], the delayed neutron fraction is 0.00740 and 0.007110 according to Gholamzadeh et al. [20] which is in agreement with the obtained results. The fraction of the delayed neutrons differs from fuel material to another. $\beta_{\text {eff }}$ was 0.0031 and 0.0069 for ${ }^{233} \mathrm{U}$ and ${ }^{235} \mathrm{U}$ materials, respectively, according to IAEA [3] which means that the $\mathrm{ThO}_{2}+\mathrm{UO}_{2}$ core is expected to have a low delayed neutron fraction and this is

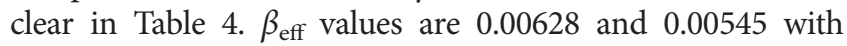
ENDF/B-VII.1 and ENDF/B-VIII falling in the expected range for $\mathrm{ThO}_{2}+\mathrm{UO}_{2}$ core.

4.2. Temperature Coefficients of Reactivity. This section discusses the reactor operation safety parameters which are the variation of the reactivity with temperatures (the temperature coefficients of reactivity). Table 4 presents the main operating safety parameters (DC and MTC). As the temperature of the moderator increases, its density decreases and lower fraction of neutrons is slowed down, resulting in negative change of reactivity. On the other hand, the neutron spectrum hardens due to the decrease of moderator fraction, which will decrease the core reactivity. The above two factors compete with each other and might lead to a negative MTC.

The DC is the most important safety parameter because it measures the reactor operation stability. The higher temperature of fuel permits the fertile material to absorb many neutrons away from the fission. ${ }^{232}$ Th absorbs larger neutrons than ${ }^{238} \mathrm{U}$ in higher fuel temperatures. Therefore, thorium-based fuel has more negative DC than the uranium fuels; this is clearly shown in Table 4. The MTC is the change in reactivity by changing the moderator temperature. The reactor is designed to have negative MTC value to provide negative reactivity feedback, which indicates that the more the temperature increases, the more the reactivity decreases. The $\mathrm{UO}_{2}$ MTC is more negative than $\mathrm{ThO}_{2}+\mathrm{UO}_{2}$; this is because of the larger fast fission cross section of U-238 than that of Th-232, and this agrees with the results in Table 3. The higher temperature of fuel permits the fertile material to 
TABLE 2: FA types, enrichment, and number loaded in the core for the first operational cycle [12].

\begin{tabular}{lccc}
\hline FA type & Average enrichment $\%$ & ${\text { No. of } \mathrm{UO}_{2} \text { rods/enrichment } \%}$ & No. of burnable absorber rods (BA) \\
\hline 16 & 1.6 & $311 / 1.6$ & - \\
24 & 2.4 & $311 / 2.4$ & - \\
36 & 3.62 & $245 / 3.7$ & 18 \\
20 B 24 & 2.4 & $66 / 3.3$ & 18 \\
36 B 24 & 2.4 & $311 / 2.4$ & 18 \\
36 B 36 & 3.62 & $311 / 2.4$ & \\
\hline
\end{tabular}

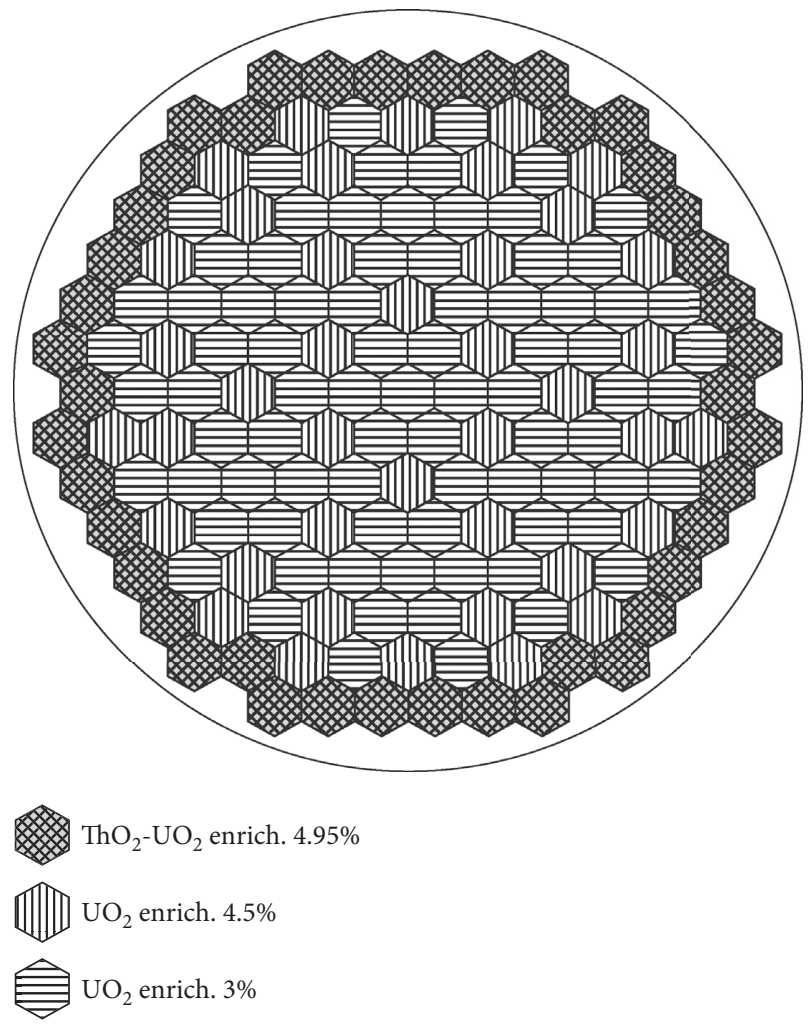

Figure 2: Mixed fuel with uranium and thorium in the $4.95 \%$ enrichment pattern core configuration.

absorb many neutrons away from the fission. Th-232 absorbs larger neutrons than U-238 in higher fuel temperatures [5].

4.3. The Middle ofLife (MOL) Results. The behavior of $k_{\text {eff }}$ over time for the VVER-1000 core can be seen in Figure 4. The calculations were performed along with 5 burnup steps of 100 days. The standard deviations for $k_{\text {eff }}$ values ranged from 0.00036 to 0.0004 for $\mathrm{UO}_{2}$ fuel and from 0.00036 to 0.00041 for $\mathrm{ThO}_{2}+\mathrm{UO}_{2}$ fuel. $k_{\text {eff }}$ values were 1.19911 and 1.23126 for $\mathrm{UO}_{2}$ and $\mathrm{ThO}_{2}+\mathrm{UO}_{2}$, respectively, at BOL. It then decreased with the depletion of the fuel. $\mathrm{ThO}_{2}+\mathrm{UO}_{2}$ core can keep criticality for more than 500 effective full power days while the $\mathrm{UO}_{2}$ core can keep criticality nearly up to 450 effective full power days. In the following figures, $\mathrm{UO}_{2}-7$ represents current results for $\mathrm{UO}_{2}$ core by ENDF/B-VII.1; $\mathrm{UO}_{2}-8$ represents current results for $\mathrm{UO}_{2}$ core by ENDF/B-VIII; UTh-7 represents current results

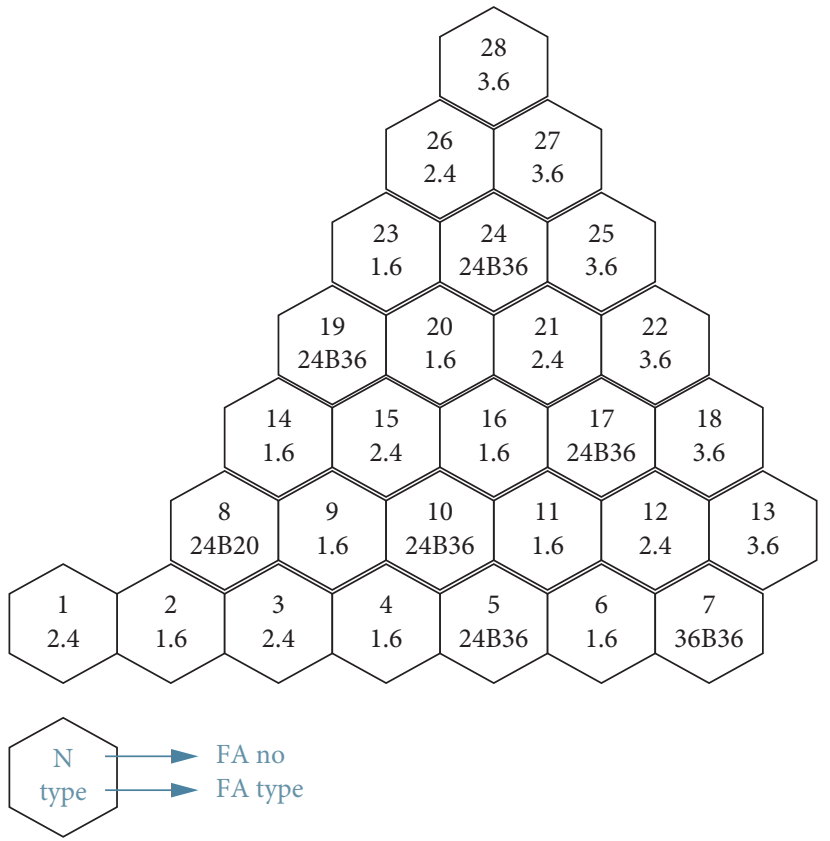

Figure 3: The VVER-1000 one-six core.

TABLE 3: TNCs values, for uranium-235, for ENDF/B-VII.1, B-VIII, and standards 2017.

\begin{tabular}{lccc}
\hline & B-VII.1 & B-VIII.0 & Standards 2017 \\
\hline$\sigma_{f}(b)$ & 584.99 & 586.80 & $587.20(1.4)$ \\
$\sigma_{\gamma}(b)$ & 98.69 & 99.40 & $99.30(2.0)$ \\
$\sigma_{e l}(b)$ & 15.11 & 14.11 & $14.09(22)$ \\
$v_{\text {tot }}$ & 2.4367 & 2.4298 & $2.4250(50)$ \\
$\alpha$ & 0.1687 & 0.1694 & 0.1690 \\
\hline
\end{tabular}

for $\mathrm{ThO}_{2}+\mathrm{UO}_{2}$ core by ENDF/B-VII.1; UTh- 8 represents current results for $\mathrm{ThO}_{2}+\mathrm{UO}_{2}$ core by ENDF/B-VIII.

As mentioned before, this simulation uses the $\mathrm{ThO}_{2}+\mathrm{UO}_{2}$ core configuration where the $3^{\text {rd }}$ fuel batch with $4.95 \%$ enrichment is composed of $50 \% \mathrm{UO}_{2}$ and $50 \% \mathrm{ThO}_{2}$. Not only the thorium amount inserted but also the thorium assemblies location in the reactor play the principal role in $k_{\text {eff }}$ value determination and the core cycle length. The thorium location in the periphery results in higher value of $k_{\text {eff }}$ and longer length of cycle [3]. 
TABLE 4: Comparison between current calculated parameters with references $[9,19,20]$.

\begin{tabular}{|c|c|c|c|}
\hline Data source & $\mathrm{DC}\left(1 /{ }^{\circ} \mathrm{C}\right)$ & $\operatorname{MTC}\left(1 /{ }^{\circ} \mathrm{C}\right)$ & $\beta_{\text {eff }}$ \\
\hline $\mathrm{UO}_{2}-7$ (current results for $\mathrm{UO}_{2}$ by ENDF/B-VII) & $-2.88 \times 10^{-5}$ & $-1.39 \times 10^{-4}$ & 0.0078 \\
\hline $\mathrm{UO}_{2}-8$ (current results for $\mathrm{UO}_{2}$ by ENDF/B-VIII) & $-2.61 \times 10^{-5}$ & $-1.13 \times 10^{-4}$ & 0.00688 \\
\hline MCNPX 2.6, ENDF/B-VI [20] & - & - & 0.00711 \\
\hline WIMSD4 [9] & $-2.04 \times 10^{-5}$ & $-1.15 \times 10^{-4}$ & - \\
\hline Reactor design [19] & $-2.11 \times 10^{-5}$ & $-1.30 \times 10^{-4}$ & 0.00740 \\
\hline UTh-7 (current results for $\mathrm{UO}_{2}+\mathrm{ThO}_{2}$ by ENDF/B-VII) & $-2.54 \times 10^{-5}$ & $-0.339 \times 10^{-4}$ & 0.00628 \\
\hline UTh-8 (current results for $\mathrm{UO}_{2}+\mathrm{ThO}_{2}$ by ENDF/B-VIII) & $-3.055 \times 10^{-5}$ & $-0.416 \times 10^{-4}$ & 0.00545 \\
\hline
\end{tabular}

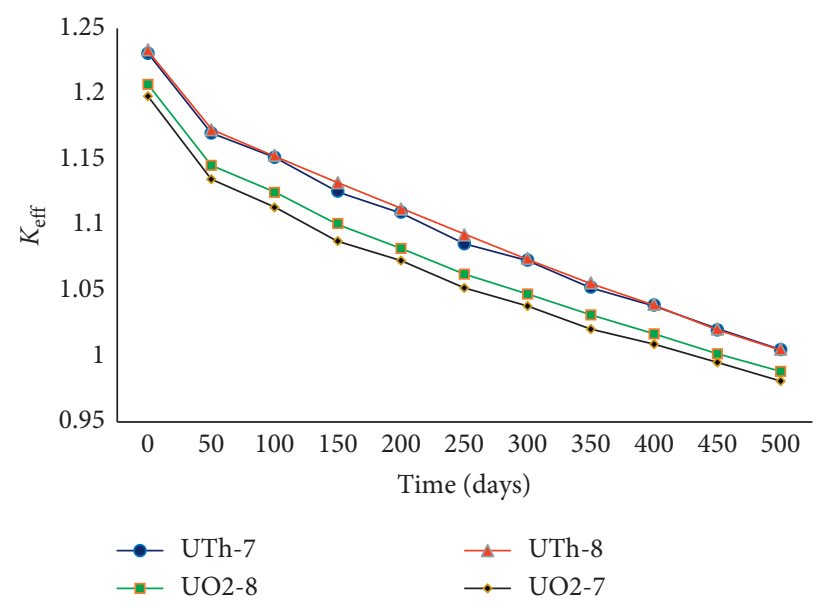

FIGURE 4: $k_{\text {eff }}$ variation with time.

After 500 effective full power days, the $\mathrm{ThO}_{2}+\mathrm{UO}_{2}$ core remains supercritical and this can be explained by the fact that since only half of the $\mathrm{UO}_{2}$ fuel is replaced with $\mathrm{ThO}_{2}$ which is located in the low neutron flux periphery assemblies. Moreover, insertion of thorium increases the first core cycle length compared with $\mathrm{UO}_{2}$ core fuel cycle, and increasing the $\mathrm{UO}_{2}$ enrichment may help this. For this reason, in order to obtain more optimum advantage of thorium, it has to be rearranged in the middle of the core. This strategy can be realized by locating $\mathrm{ThO}_{2}$ in the core periphery for the first operational cycle and then shuffling them into the core interior in the subsequent cycles.

Thorium was mixed with ${ }^{235} \mathrm{U}$ to provide power till building enough ${ }^{233} \mathrm{U}$ amounts. Figure 5 illustrates the change in the burnup rate over time. As time passes, the burnup rate increases till it reaches 20.13 and $21.3 \mathrm{GWD} /$ MTU for the $\mathrm{UO}_{2}$ and $\mathrm{ThO}_{2}+\mathrm{UO}_{2}$ one-six core, respectively, at end of life (EOL). Figure 5 shows that the core burnup results of ENDF/B-VII.1library are typically the results of the ENDF/B-VIII library, and the changes appear only in the criticality calculations.

4.4. The End of Life (EOL) Results. The ${ }^{235} \mathrm{U}$ is the core fissionable material in that it steadily decreases as it burns over the lifetime of the core, in addition to increasing the output of ${ }^{239} \mathrm{Pu}$ and ${ }^{240} \mathrm{Pu}$ levels towards the EOL. The fissile component ${ }^{235} \mathrm{U}$ is depleted from the startup until EOL, and other fissile components are created when ${ }^{238} \mathrm{U}$ is

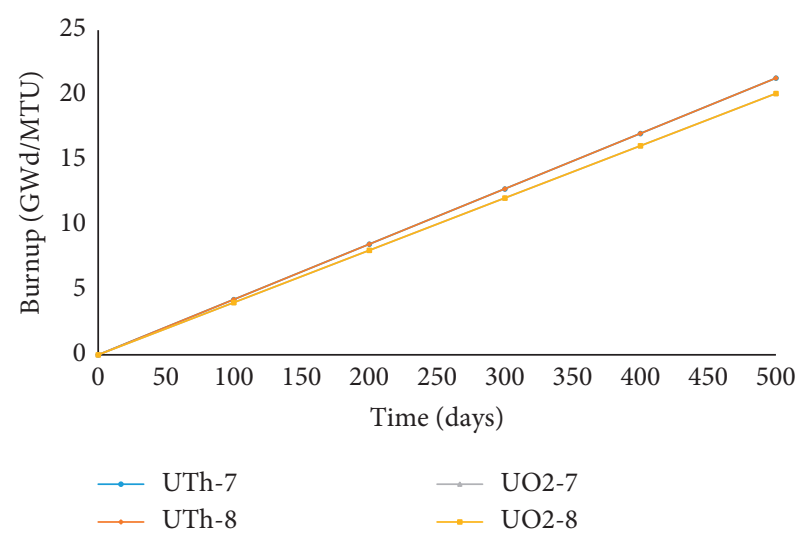

Figure 5: The change in the burnup over time for one-six core.

transmuted to higher actinides, especially ${ }^{239} \mathrm{Pu}$ and ${ }^{240} \mathrm{Pu}$. The quantity of total fission products (FPs) in the core grows up as the burnup level increases. FPs are neutron absorbers which have a strong adverse effect on the neutron economy of the core as time passes. Figures 6 and 7 show the fuel consumption and the production of actinides that build up in the $\mathrm{UO}_{2}$ and $\mathrm{ThO}_{2}+\mathrm{UO}_{2}$ cores.

The $\mathrm{UO}_{2}$ core contains ${ }^{235} \mathrm{U}+{ }^{238} \mathrm{U}$; the two isotopes were re-evaluated in the ENDF/B-VIII library which means marginal differences in results, and this appears in Figure 6(a) especially for the consumption of ${ }^{235} \mathrm{U}$. On the other hand, ENDF/B-VIII did not re-evaluate thorium. The 


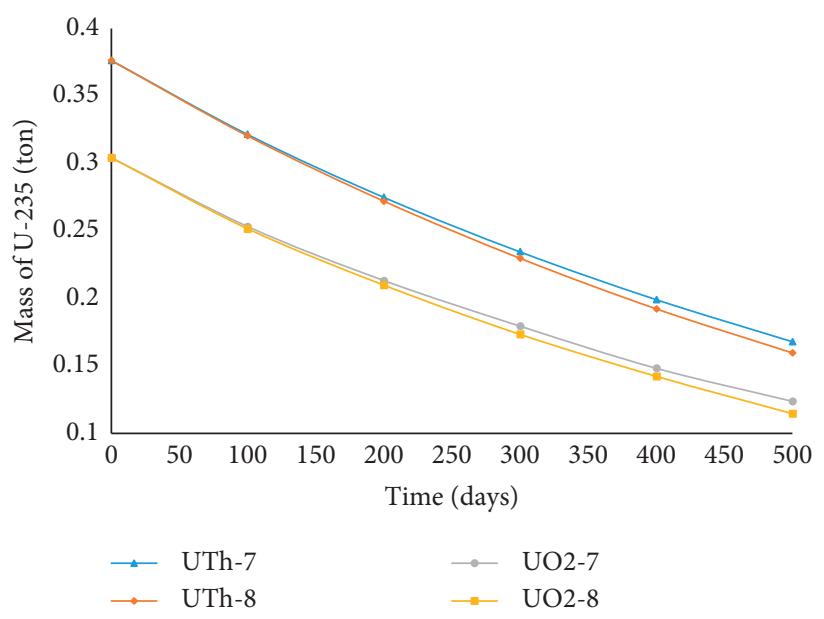

(a)

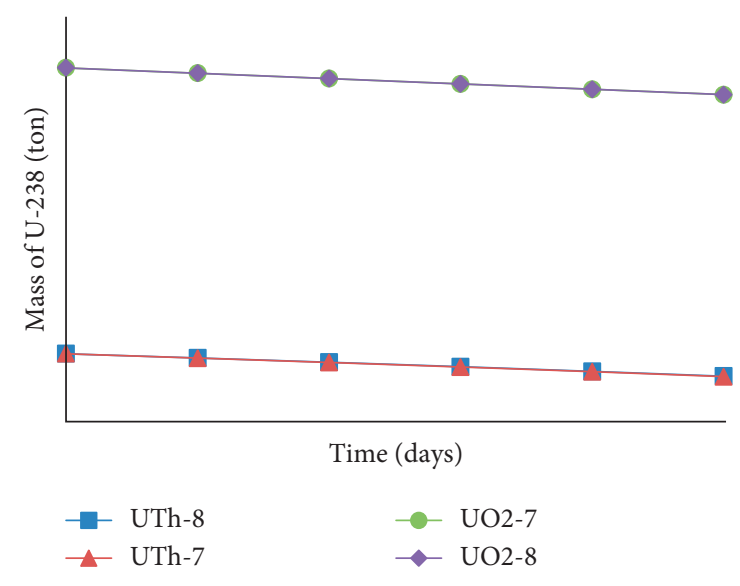

(b)

Figure 6: The fuel consumption.

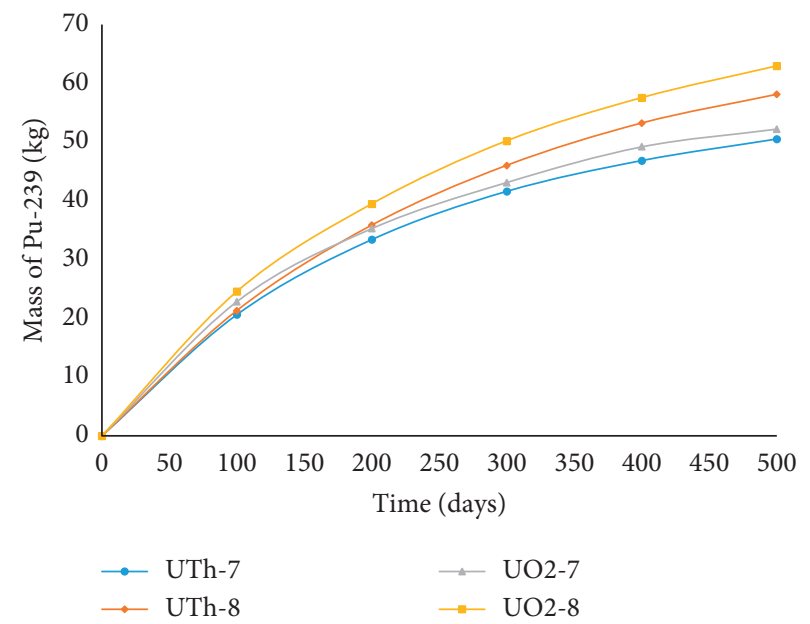

(a)

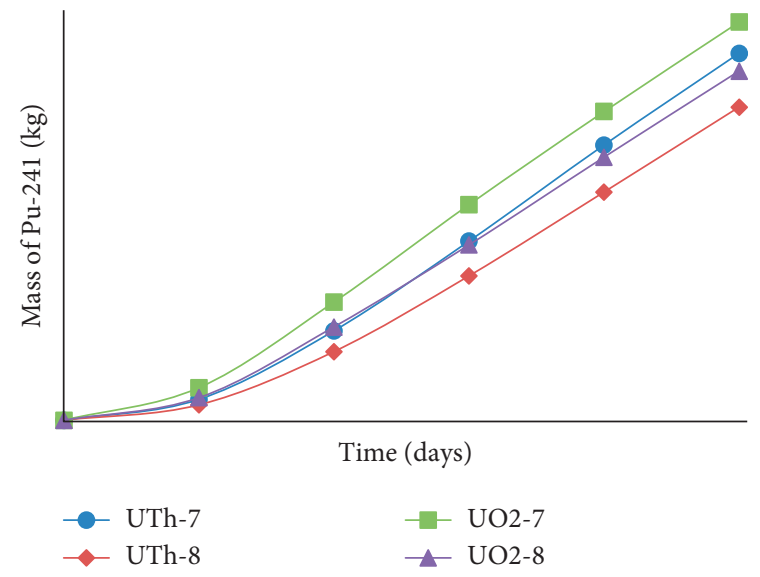

(c)

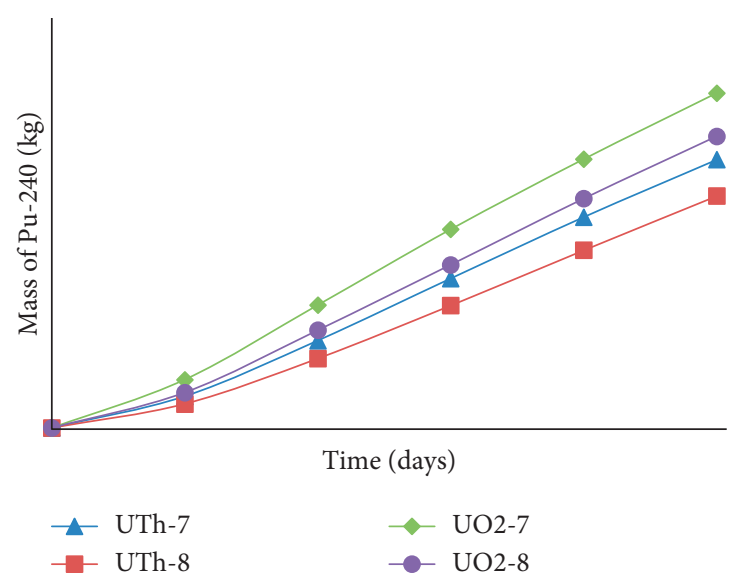

(b)

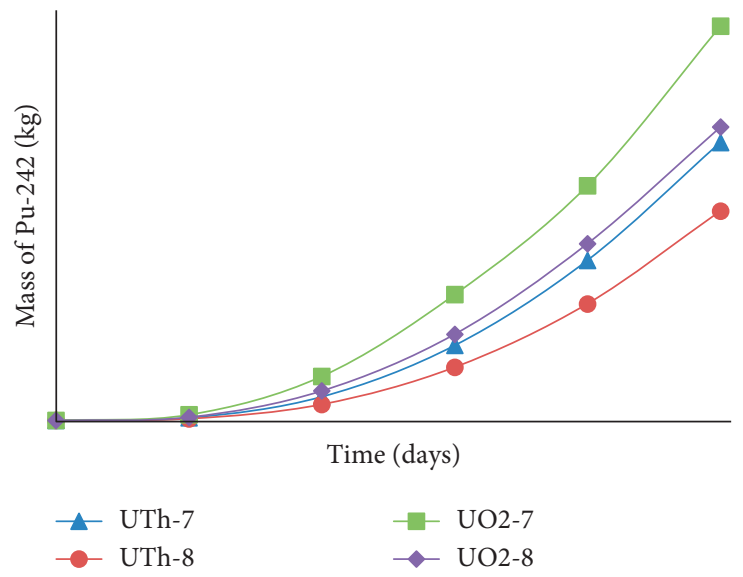

(d)

Figure 7: Production of actinides. 


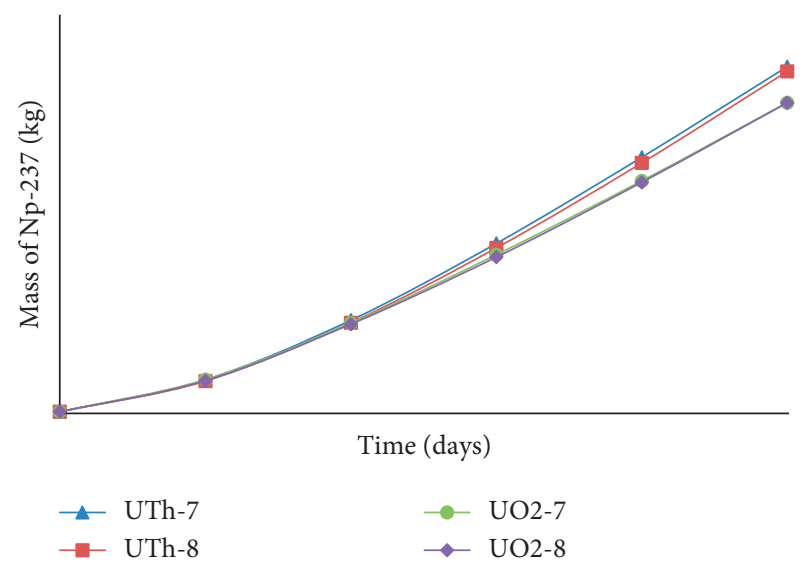

Figure 8: Neptunium production.

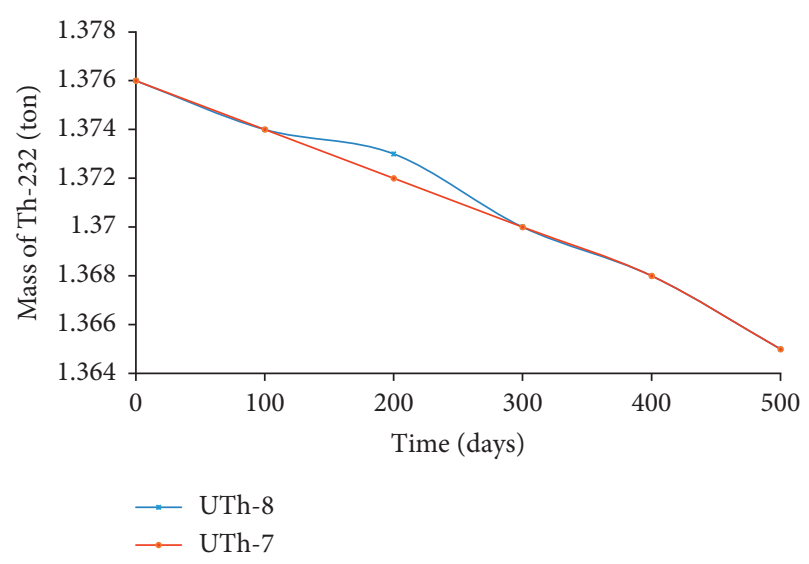

FIgURE 9: The thorium consumptions.

thorium core contains ${ }^{235} \mathrm{U}+{ }^{238} \mathrm{U}+{ }^{232} \mathrm{Th}$, hence the slight difference in the UTh-7 and UTh-8 mainly from ${ }^{235} \mathrm{U}+{ }^{238} \mathrm{U}$ cross section difference. The principal benefit of using thorium as a fuel option is to get as much fissile isotope ${ }^{233} \mathrm{U}$ as possible and eliminate the plutonium production, and this is clearly demonstrated in Figure 7.

Figure 8 shows the neptunium isotope masses produced during the reactor operational cycle. Figure 9 presents the consumption of thorium in the $\mathrm{ThO} 2+\mathrm{UO} 2$ core. There was a thorium consumption difference between ENDF/B-VII.1 and ENDF/B-VIII at 200 days, but we do not have any explanation for this difference.

\section{Conclusion}

From the beginning of life to the end of life, the VVER-1000 neutronic parameters were calculated using MCNP6 code. These parameters were determined for a $\mathrm{UO}_{2}$ and a mixed $\mathrm{ThO}_{2}+\mathrm{UO}_{2}$ fuel. The obtained results fall within an acceptable range with respect to the reactor design parameters and the published data. The delayed neutron fraction $\beta_{\text {eff }}$ values were found to be 0.0078 and 0.00688 for $\mathrm{UO}_{2}$ fuel, with ENDF/B-VII.1 and ENDF/B-VIII, respectively, which are in an agreement with the reference value of 0.00740 . On the other hand, $\mathrm{ThO}_{2}+\mathrm{UO}_{2}$ has lower delayed neutron fraction $\beta_{\text {eff }}$ values $(0.00628$ and 0.00545$)$ than $\mathrm{UO}_{2}$ fuel. For the $\mathrm{UO}_{2}$ fuel, its MTC value was $-1.39 \times 10^{-4} 1\left({ }^{\circ} \mathrm{C}\right)$ while for the $\mathrm{ThO}_{2}+\mathrm{UO}_{2}$ fuel, it was $-0.339 \times 10^{-4}\left({ }^{\circ} \mathrm{C}\right)$ with $\mathrm{ENDF} / \mathrm{B}-$ VII.1. All fall in the reactor design operational limits. It has been shown that the MTC of the $\mathrm{UO}_{2}$ core is more negative than that of the $\mathrm{ThO}_{2}+\mathrm{UO}_{2}$ one; this is because of the larger fast fission cross section of ${ }^{238} \mathrm{U}$ than that of ${ }^{232} \mathrm{Th}$. Thoriumbased fuel has more negative DC than the uranium fuels. The behavior of $k_{\text {eff }}$ over time for both cores explained the slight increment of ENDF/B-VIII than ENDF/B-VII.1 in the criticality calculations for the $\mathrm{UO}_{2}$ fuel. $k_{\text {eff }}$ decreased with the depletion of the fuel indicating that the $\mathrm{UO}_{2}$ core has to be refueled earlier than the $\mathrm{ThO}_{2}+\mathrm{UO}_{2}$ core for the first cycle of operation. The plutonium isotopes produced due to the $\mathrm{ThO}_{2}+\mathrm{UO}_{2}$ core were lower than those of the $\mathrm{UO}_{2}$ core.

\section{Data Availability}

The data used to support the findings of this study are included within the article.

\section{Conflicts of Interest}

The authors declare that they have no conflicts of interest.

\section{References}

[1] G. P. Nyalunga, "Developing a Fresh core neutronic model at 300K for a VVER-1000 reactor type using MCNP6," Master's Thesis, Potchefstroom Campus of the North-West University, Potchefstroom, South Africa, 2016.

[2] T. Lotsch, V. Khalimonchuk, and A. Kuchin, Proposal of a Benchmark for Core Burnup Calculations for a VVER-1000 Reactor Core, International Atomic Energy Agency, Vienna, Austria, 2009, http://www.iaea.org/inis/collection/ NCLCollectionStore/_Public/41/035/41035568.pdf.

[3] International Atomic Energy Agency, Thorium Fuel Cycle Potential Benefits and Challenges, IAEA-TECDOC-1450, Vienna, Austria, 2005.

[4] M. S. Dwiddar, A. A. Badawi, H. H. Abou-Gabal, and I. A. ElOsery, "Investigation of different scenarios of thorium-uranium fuel distribution in the VVER-1200 first core," Annals of Nuclear Energy, vol. 85, pp. 605-612, 2015.

[5] A. A. Galahom, "Minimization of the fission product waste by using thorium based fuel instead of uranium dioxide," $\mathrm{Nu}$ clear Engineering and Design, vol. 314, pp. 165-172, 2017.

[6] A. A. Galahom, "Improvement of the VVER-1200 fuel cycle by introducing thorium with different fissile material in blanket-seed assembly," Nuclear Science and Engineering, vol. 193, no. 6, pp. 638-651, 2019.

[7] J. R. Maiorino, G. L. Stefani, J. M. L. Moreira, P. C. R. Rossi, and T. A. Santos, "Feasibility to convert an advanced PWR from UO 2 to a mixed U/ThO 2 core-Part I: parametric studies," Annals of Nuclear Energy, vol. 102, pp. 47-55, 2017.

[8] A. Pirouzmand and M. Kazem Dehdashti, "Estimation of relative power distribution and power peaking factor in a VVER-1000 reactor core using artificial neural networks," Progress in Nuclear Energy, vol. 85, pp. 17-27, 2015.

[9] M. Aghaie, A. Zolfaghari, and A. Minuchehr, "Coupled neutronic thermal-hydraulic transient analysis of accidents in PWRs," Annals of Nuclear Energy, vol. 50, pp. 158-166, 2012. 
[10] M. Jabbari, K. Hadad, G. R. Ansarifar, Z. Tabadar, and M. Hashemi-Tilehnoee, "Power calculation of VVER-1000 reactor using a thermal method, applied to primary-secondary circuits," Annals of Nuclear Energy, vol. 77, pp. 129-132, 2015.

[11] T. Lotsch, V. Khalimonchuk, and A. Kuchin, Solutions for the Task 1 and Task 2 of the Benchmark for Core Burnup Calculations for a VVER-1000 Reactor, International Atomic Energy Agency, Vienna, Austria, 2011.

[12] M. R. Karahroudiand and S. A. M. Shirazi, "Study of power distribution in the CZP, HFP and normal operation states of VVER-1000 (Bushehr) nuclear reactor core by coupling nuclear codes," Annals of Nuclear Energy, vol. 75, pp. 38-43, 2015.

[13] D. B. Pelowitz, MCNP6 ${ }^{\mathrm{TM}}$ User's Manual, Version 1.0, Elsevier, Amsterdam, Netherlands, (LA-CP-13-00634), 2013.

[14] R. Capote and A. Trkov, "IAEA CIELO evaluation of neutroninduced reactions on ${ }^{235} \mathrm{U}$ and ${ }^{238} \mathrm{U}$ targets for incident energies up to $30 \mathrm{MeV}$," Nuclear Data Sheets, vol. 148, pp. 148-254, 2018.

[15] J. L. Conlin, W. Haeck, D. Neudecker, D. K. Parsons, and M. C. White, Release of ENDF/B-VIII.0-Based ACE Data Files, XCP-5, Los Alamos National Laboratory, Los Alamos, NM, USA, (LA-UR-18-24034), 2018.

[16] D. A. Brown, "ENDF/B-VIII.0: the $8^{\text {th }}$ major release of the nuclear reaction data library with CIELO-project cross sections, new standards and thermal scattering data," Nuclear Data Sheets, vol. 148, 2018.

[17] M. B. ChadwickR. Capote et al., "CIELO collaboration summary results: international evaluations of neutron reactions on uranium, plutonium, iron, oxygen and hydrogen," Nuclear Data Sheets, vol. 148, 2018.

[18] S. M. Reda, I. M. Gomaa, I. I. Bashter, and E. A. Amin, "Effect of MOX fuel and the ENDF/B-viii on the AP1000Neutronic parameters calculations by using MCNP6," Nuclear Technology \& Radiation Protection, vol. 34, no. 4, pp. 325-335, 2019.

[19] Russia Federal Agency on Nuclear Energy (FRANE), "Final safety assessment report (FSAR) for BNPP," Accident Analysis, Vol. 4, Russia Federal Agency on Nuclear Energy, Moscow, Russia, 2005.

[20] Z. Gholamzadeh, S. A. Hossein Feghhi, L. Soltani, M. Rezazadeh, C. Tenreiro, and M. Joharifard, "Burn-up calculation of different thorium-based fuel matrixes in a thermal research reactor using MCNPX 2.6 code," Nukleonika, vol. 59, no. 4, pp. 129-136, 2014.

[21] G. Farkas, S. Michálek, and J. Hašcık, "MCNP5 delayed neutron fraction $\left(\beta_{\text {eff }}\right)$ calculation in training reactor VR-1," Journal of Electrical Engineering, vol. 59, no. 4, pp. 221-224, 2008.

[22] W. Compton, "Impact of configuration variations on small modular reactor core performance," M.Sc. thesis, Missouri University of Science and Technology, Rolla, Missouri, 2015.

[23] J. R. Lamarsh and A. J. Baratta, Introduction to Nuclear Engineering, Prentice Hall Inc., Hoboken, NJ, USA, Third edition, 2001. 